\title{
US medical and surgical society position statements on physician-assisted suicide and euthanasia: a review
}

\author{
Joseph G. Barsness ${ }^{3}$, Casey R. Regnier ${ }^{4}$, C. Christopher Hook ${ }^{1}$ and Paul S. Mueller ${ }^{2 *}$ (i)
}

\begin{abstract}
Background: An analysis of the position statements of secular US medical and surgical professional societies on physician-assisted suicide (PAS) and euthanasia have not been published recently. Available statements were evaluated for position, content, and sentiment.

Methods: In order to create a comprehensive list of secular medical and surgical societies, the results of a systematic search using Google were cross-referenced with a list of societies that have a seat on the American Medical Association House of Delegates. Societies with position statements were identified. These statements were divided into 5 categories: opposed to PAS and/or euthanasia, studied neutrality, supportive, acknowledgement without statement, and no statement. Linguistic analysis was performed using RapidMinder in order to determine word frequency and sentiment respective to individual statements. To ensure accuracy, only statements with word counts $>100$ were analyzed. A 2-tailed independent $t$ test was used to test for variance among sentiment scores of opposing and studied neutrality statements.
\end{abstract}

Results: Of 150 societies, only 12 (8\%) have position statements on PAS and euthanasia: 11 for PAS (5 opposing and 4 studied neutrality) and 9 for euthanasia (6 opposing and 2 studied neutrality). Although the most popular words used in opposing and studied neutrality statements are similar, notable exceptions exist (suicide, medicine, and treatment appear frequently in opposing statements, but not in studied neutrality statements, whereas psychologists, law, and individuals appear frequently in studied neutrality statements, but not in opposing statements). Sentiment scores for opposing and studied neutrality statements do not differ (mean, 0.094 vs. 0.104; $P=0.90$ ).

Conclusions: Few US medical and surgical societies have position statements on PAS and euthanasia. Among them, opposing and studied neutrality statements share similar linguistic sentiment. Opposing and studied neutrality statements have clear differences, but share recommendations. Both opposing and studied neutrality statements cite potential risks of PAS legalization and suggest that good palliative care might diminish a patient's desire for PAS.

Keywords: Assisted death, Euthanasia, PAD, PAS, Physician-assisted suicide

*Correspondence: mueller.pauls@mayo.edu

2 Department of Internal Medicine, Mayo Clinic Health System-Franciscan

Healthcare in La Crosse, 800 West Ave S, La Crosse, WI 54601, USA

Full list of author information is available at the end of the article

\begin{abstract}
Background
Physician-assisted suicide (PAS) and euthanasia are highly debated and controversial topics in the United States. In PAS, a patient ingests a drug prescribed by a physician for the purpose of causing the patient's death, in order to relieve unacceptable symptoms or quality of life. Currently, California [1], Colorado [2], Hawaii [3],
\end{abstract}


Maine [4], Oregon [5], Vermont [6], Washington [7], and the District of Columbia [8] have legalized PAS. (The Montana Supreme Court ruled that PAS does not conflict with Montana public policy [9]) The other US states prohibit PAS and punish it by law [10]. In euthanasia, a physician (or someone else) administers a lethal drug. Euthanasia is illegal throughout the United States [10].

Laws concerning PAS, also known as physician-assisted death (PAD), are generally more rigid in the United States than in countries where PAD is legal. For instance, in the Netherlands, PAS and euthanasia are legal for adults (or for persons age 12 through 17 years with parental involvement). Requests for PAD "often come from patients experiencing unbearable suffering with no prospect of improvement. Their request must be made earnestly and with full conviction... However, patients have no absolute right to euthanasia and doctors no absolute duty to perform it" [11]. Currently, no US state allows PAS for persons younger than 18 years, and PAS is illegal in the absence of a severe physical ailment that will result in natural death within 6 months $[1-3,5-8]$. The ethical permissibility of PAS and euthanasia, along with considerations regarding what constitutes patient autonomy in decision-making associated with the dying process, creates an emotionally provocative and divisive debate. The position statements of medical and surgical professional societies concerning PAS and euthanasia may reflect complexities.

The statements of professional societies guide clinicians on various topics, such as disease prevention and management. For PAS and euthanasia, such statements inform, provide multiple (sometimes opposing) perspectives, and advocate for specific positions. Because PAS and euthanasia involve physician action, physicians understandably may turn to their professional societies for guidance on these topics. A comprehensive analysis of such statements issued by secular US medical and surgical professional societies has not been published recently. Therefore, in this cross-sectional study, we determined the number of secular US societies that have position statements about PAS and euthanasia and the positions they have taken. We also analyzed the contents and conducted a linguistic analysis of the statements.

\section{Methods}

We developed a comprehensive list of secular US medical and surgical professional societies with use of 2 methods. To do so, we first conducted a systematic Google search using the phrase "American [...] medical societies," with the bracket including a name of a specialty derived from the Mayo Clinic directory. An original search was performed for each specialty in the directory, and the respective first 2 Google search pages were analyzed for societies. Second, we obtained a list of specialty societies from the American Medical Association (AMA) website [12]. This list reflects organizations entitled to a seat in the AMA House of Delegates. It served to provide a cross-reference for our Google search results. In a combination of these 2 methods, a comprehensive list was created of the US specialty-based medical and surgical professional societies.

We determined the positions of these societies on PAS or euthanasia, or both. These positions were organized into 5 categories: supportive, opposed, studied neutrality, acknowledgement without statement, and no statement. Studied neutrality position statements are characterized by an understanding of the practical concerns associated with PAS or euthanasia and the persistent desire of some patients for PAS or euthanasia despite these concerns. The American Academy of Hospice and Palliative Medicine (AAHPM) position statement [13] exemplifies a studied neutrality statement. To determine whether a society had publicly issued a position statement on PAS or euthanasia, or both, the society's official website was consulted. If no such statement was available on the website, an email was sent to a society contact listed on the website. If the society website did not provide a statement and no official position statement was publicly available, the society was categorized as having no statement.

For each available position statement, linguistic analysis was performed using a data science software platform (RapidMiner; RapidMiner) [14]. From each statement, so-called stop words (such as is, $a$, or the) and the name of the society were filtered out because these words provided no insights into the intent of the statement authors. The other words were sorted by frequency of use, producing a chart of each statement's top word choices. In addition, a given statement's words that were used more than once were processed by a sentiment analysis tool (Twinword; Twinword Inc). This approach relates word choice to emotional attitude and generates a quantitative score of emotional positivity. Medhat et al. [15] provided a comprehensive survey of sentiment analysis approaches, including a description of the dictionarybased approach used in the present study. To ensure the tool's generated score was reflective of the statement, we analyzed only the statements with more than 100 words. A mean score was generated for opposing statements and studied neutrality statements. Sentiment scores were compared among the opposing and studied neutrality statements with a 2 -tailed independent $t$ test.

\section{Results}

Our search methodology identified a total of 150 distinct secular US medical and surgical professional societies (Additional file 1: Table S1). Of these, only $12(8 \%)$ had 
position statements regarding PAS or euthanasia, or both (Table 1). Eleven societies (7\%) had statements on PAS. Of these, 5 (45\%) had positions opposing PAS; 4 (36\%), positions of studied neutrality; and 2 (18\%), acknowledgment of PAS without a position. No society had a statement overtly in support of PAS. Regarding euthanasia, 9 societies $(6 \%)$ had position statements: $6(67 \%)$, positions opposing euthanasia; 2 (22\%), positions of studied neutrality; and 1 (11\%), acknowledgement of euthanasia without a position. No society had a statement overtly supporting euthanasia. Three societies have had their position statements published in peer-reviewed journals (American Academy of Neurology [AAN] [16], American College of Obstetricians and Gynecologists [17], and American College of Physicians [ACP] [19]).

The most popular words used in opposing position statements and studied neutrality statements are shown in Figs. 1 and 2. Suicide, medicine, and treatment appear frequently in opposing statements but not in studied neutrality statements. By comparison, psychologists, law, and individuals appear frequently in studied neutrality statements but not in opposing statements. Otherwise, the words used in these 2 statement types are similar. In linguistic analysis, the mean sentiment score was 0.094 for opposing statements and 0.104 for studied neutrality statements, a nonsignificant difference $(P=0.90)$. Of note, Twinword categorizes any sentiment score below -0.05 as negative and any score above 0.05 as positive [28]. Thus, given the mean scores in this study, the opposing and studied neutrality statements both used emotionally positive language.

From a content standpoint, the opposing statements generally argue that PAS is problematic in practice and

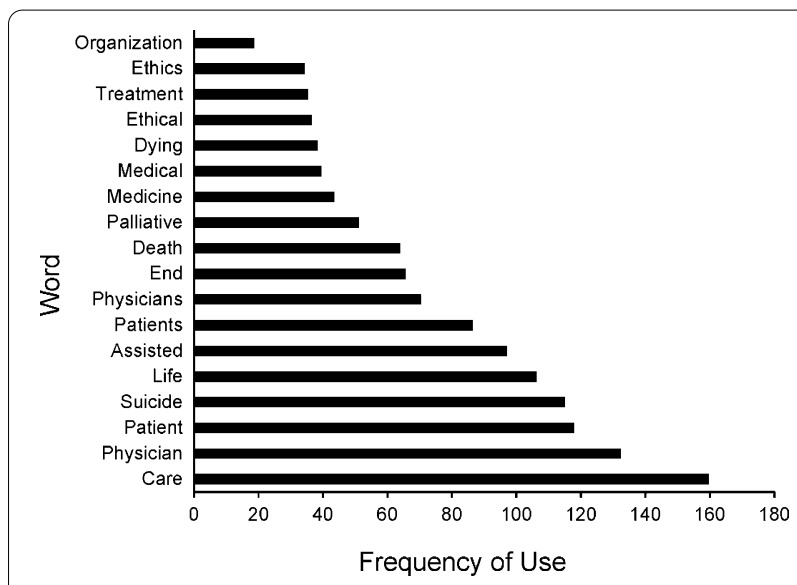

Fig. 1 Most popular words in opposing position statements among 150 US medical and surgical professional societies

in society. The statements of the Society for Post-Acute and Long-term Care Medicine (AMDA), ACP, AMA, and the American Society of Anesthesiologists (ASA) assert that PAS contradicts the healing role of the physician $[19,20,25,27]$. To counter the claim that PAS is a legitimate approach to symptom control in extreme cases, the statements of AMDA, ACP, and the National Hospice and Palliative Care Organization (NHPCO) highlight the legal permissibility of palliative sedation. Finally, ACP and NHPCO mention that the US Supreme Court has ruled that no legal right to PAS exists. Studied neutrality statements provide supportive and cautionary arguments concerning PAS. The statements of AAHPM, AAN, and the American Pharmacists Association acknowledge the complexities of the physician-patient relationship [13,

Table 1 Positions on PAS and Euthanasia of US medical and surgical specialty societies with position statements

\begin{tabular}{lll}
\hline Society & Position statements & Euthanasia \\
\cline { 2 - 3 } & PAS & No statement \\
\hline American Academy of Hospice and Palliative Medicine [13] & Studied neutrality & Opposed \\
American Academy of Neurology [16] & Studied neutrality & Acknowledge \\
American College of Obstetricians and Gynecologists [17] & Acknowledge & Opposed \\
American College of Pediatricians [18] & No statement & Opposed \\
American College of Physicians [19] & Opposed & Opposed \\
American Medical Association [20, 21] & Opposed & Studied neutrality \\
American Pharmacists Association [22] & Studied neutrality & Opposed \\
American Psychiatric Association [23] & Acknowledge & Studied neutrality \\
American Psychological Association [24] & Studied neutrality & No statement \\
American Society of Anesthesiologists [25] & Opposed & No statement \\
National Hospice and Palliative Care Organization [26] & Opposed & Opposed \\
Society for Post-Acute and Long-term Care Medicine [27] & Opposed & \\
\hline PAS & &
\end{tabular}

PAS physician-assisted suicide 


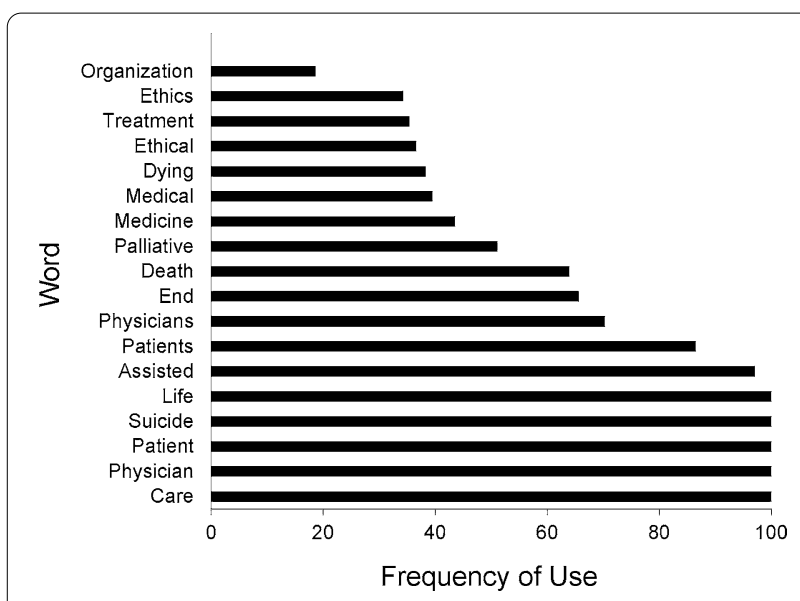

Fig. 2 Most popular words in studied neutrality position statements among 150 US medical and surgical professional societies

16, 22], and American Psychological Association (APA) acknowledges the social complexities of the medical environment [24]. Each of these statements emphasizes patient autonomy in decision-making associated with the dying process.

The studied neutrality statements generally support further study of palliative care techniques or physician ethics training, or a combination. Opposing statements (ACP [19] and AMA [20]) and studied neutrality statements (AAHPM [13] and AAN [16]) warn of potential long-term societal risks associated with a legalization of PAS (e.g., slippery slope). Opposing statements (AMDA [27], ACP [19], and NHPCO [26]) and 1 studied neutrality statement (APA [24]) suggest that effective palliative care can diminish a patient's desire for PAS.

\section{Discussion}

This study has several key findings. First, of 150 secular US medical and surgical professional societies, only 12 (8\%) have position statements on PAS and euthanasia: 11 for PAS ( 5 opposing and 4 studied neutrality) and 9 for euthanasia ( 6 opposing and 2 studied neutrality). Only 3 of these statements have been published in peer-reviewed journals. Second, opposing and studied neutrality statements use similar linguistic sentiment. Third, although opposing and studied neutrality statements have clear differences, they also share recommendations.

It is unclear why so few US societies have position statements on PAS and euthanasia. A given society's lack of a statement regarding these topics may be due to numerous factors. For example, large and influential societies such as AMA and ACP have position statements on PAS and euthanasia, potentially inhibiting smaller societies from taking positions or causing the smaller societies to perceive their taking a position as unnecessary or irrelevant. Indeed, in personal communications with representatives of societies that do not have position statements, some representatives directed us to the AMA website (J. Barsness, written communication, June 2018). Society specialty may be another factor. For example, in an email from a specialized surgical society, the contact cited the highly specialized field of its members as a reason for not having a position statement (J. Barsness, written communication, June 2018). These phenomena, along with the controversy surrounding the topics, may discourage a society from creating a position statement about PAS or euthanasia (or both).

No position statement argued in favor of PAS or euthanasia. In consideration of a general desire to avoid controversy, a position of studied neutrality may be perceived by a professional society as the only feasible alternative to an opposing position. The decisions of several societies to acknowledge PAS or euthanasia without taking a position appear similar in intent. Either ethical uncertainty exists in the field or the societies believe the need exists to suppress potentially controversial statements.

Among available position statements, linguistic trends are apparent. Societies with studied neutrality positions emphasize patient autonomy regarding end-of-life decision-making but also respect the physician's role as a health care provider and recognize the benefit of palliative care $[16,24]$. The AAN, which takes a studied neutral position, reasons that,

\section{"The Ethics, Law, and Humanities Committee endorses the belief that the primary role of a physi- cian is to prevent and treat disease whenever pos- sible. At the same time, the committee strongly endorses the provision of palliative care to alleviate suffering in patients with illnesses that are unre- sponsive to disease-specific treatments" [16].}

Studied neutrality statements typically call for rigorous ethical training and further study of palliative care and PAS. This call leaves open the possibility of further analysis [17]. The APA, taking a studied neutrality position, reasons, "[We] encourage psychologists to obtain training in ethics (e.g., medical ethics, professional codes of conduct) in the context of diversity, as applied to palliative and end-of-life decisions and care" [24].

Societies with opposing statements view PAS as contrary to the physician's role in the general US society, do not view death as a right, and view that patient autonomy is an insufficient reason for legalization of PAS. The statements of the AMDA, ACP, AMA, and ASA posit that PAS contradicts the role of a physician [19, 20, 25, 27]. The ACP position statement provides illustrative reasoning: "Physician-assisted suicide requires physicians to 
breach specific prohibitions as well as the general duties of beneficence and nonmaleficence. Such breaches are viewed as inconsistent with the physician's role as healer and comforter" [19]. Unsurprisingly, the opposing statements do not mention further study of PAS. Statements that oppose euthanasia follow similar reasoning.

Some opposing statements (of AMDA, ACP, and NHPCO) reference the permissibility of palliative sedation to counter the claim that PAS is a legitimate symptom management approach in the case of extreme discomfort [19, 26, 27]. In such cases, patients should receive aggressive palliation. AMDA reasons, "AMDA supports aggressive treatment toward relieving the pain, anxiety, depression, emotional isolation, and other physical symptoms that can accompany the dying process even if the unintended result of such treatment may hasten the patient's death" [27]. The ACP and NHPCO statements also highlight the US Supreme Court's prior ruling that there is no right to die (or PAS) in the United States [19, 26].

Of note, studied neutrality statements (AAHPM and AAN) $[13,16]$ and opposing statements (ACP and AMA) $[19,20]$ warn of a slippery slope of long-term risks that PAS legalization may incur. The ACP opposing statement says, "Although the ACP's fundamental concerns are based on ethical principles, research suggests that a 'slippery slope' exists in jurisdictions where physician-assisted suicide and euthanasia are legal" [19]. The AAHPM's studied neutral statement says, "Such a change risks unintended long-range consequences that may not yet be discernible, including effects on the relationship between medicine and society" [13]. Such longrange consequences include broadened use of PAS for nonterminal conditions and use of PAS in favor of palliative care. Additionally, the studied neutrality and opposing statements suggest that effective palliative care can diminish a patient's desire for PAD [19, 24, 27, 29]. The AAN's studied neutrality statement says,

\section{"[The committee] expresses support for improved availability of palliative care services, palliative care education for AAN members, and palliative care research intended to identify more effective means to alleviate refractory suffering of dying patients. By doing so, it hopes to minimize future patient interest in hastened death" [16].}

The language of position statements correlates with the position taken by the societies. For instance, studied neutrality statements refrain from the word suicide and instead use such terms as hastened death or assisted death $[13,16,24]$. This use of language is justified in the AAN statement as a means of reducing stigma associated with PAS [16]. Alternative terminology regarding
PAS has been actively considered in the literature [30]. In contrast, the ACP opposing statement states a rationalization of use of the word suicide as not being derogatory and aiding in clarity in the discussion of the topic (e.g., in contrast to "physician aid in dying," which could refer to palliative care, terminal sedation, PAS, and euthanasia) [19]. Unsurprisingly, statements that oppose PAS or euthanasia (or both) use the word suicide more frequently [19-21, 27, 29]. In contrast, studied neutrality statements use psychologists, law, and individuals more frequently than opposing statements-likely a reflection of the procedures used to request PAS and the emphasis on patient autonomy in association with PAS. That said, the most popular words used in the opposing statements and studied neutrality statements are similar.

Statements have considered the culturally and historically negative connotations of the term suicide [19]. Recognizing these connotations, we sought to explore whether the opposing statements' preference for referring to PAS as a suicide and studied neutrality statements' preference for alternative terms such as assisted death indicates a statement's comprehensive use of emotionally positive or negative language. Therefore, we extended the linguistic analysis by exploring possible associations between linguistic sentiment and statement position through comparison of mean sentiment scores across position categories. Although studied neutrality statements commonly use phrases such as assisted death in place of suicide, our linguistic analysis showed similar mean sentiment scores for studied neutrality statements and opposing statements. Furthermore, both opposing and studied neutrality statements tended to use emotionally positive language.

Nonetheless, our analysis and findings provide no insight into the rhetorical decision to use the label suicide or an alternate. Rather, our findings suggest that use of suicide or an alternate term such as assisted death does not indicate that a position statement intentionally uses emotionally positive or negative language.

\section{Limitations}

A limitation of the present analysis is the small number of position statements of the organizations. Corpusbased sentiment analysis would provide a better understanding of author intent in the statements because this approach has the ability to consider phrase context more thoroughly [15]. That said, we did not use this type of analysis because the authors of these position statements were unlikely to use techniques such as sarcasm or irony. In addition, we did not include position statements from societies with religious affiliations, some of which have large memberships (e.g., Christian Medical and Dental Associations [31]). Because our study focused on position 
statements of US professional societies, we intentionally did not include statements from non-US-based societies. Nonetheless, given the variability of perspectives and laws on PAS and euthanasia globally, a study comparing US with non-US statements should be considered.

\section{Conclusions}

Only a dozen secular US medical and surgical professional societies have position statements on PAS and euthanasia, and only 3 of these statements have been published in peer-reviewed journals. The reasons for these small numbers are unclear but may be related to the controversial nature of the topics, the positions of large and influential societies, and the relevancy of the topics for specific specialty societies.

Aside from the use of the words suicide, medicine, and treatment in opposing statements and the words psychologists, law, and individuals in studied neutrality statements, the most popular words used in opposing and studied neutrality position statements are similar. Use of the word suicide or assisted death does not appear to indicate a statement's comprehensive use of emotionally positive or negative language.

Opposing statements generally claim PAS contradicts the healing role of the physician and that alternative approaches to symptom control exist for extreme cases (e.g., palliative sedation). Studied neutrality statements highlight patient autonomy in decision-making associated with the dying process. The opposing statements and the studied neutrality statements cite potential longterm societal risks associated with legalization of PAS and suggest that effective palliative care can diminish a patient's desire for PAS.

\section{Supplementary information}

Supplementary information accompanies this paper at https://doi. org/10.1186/s12910-020-00556-5.

Additional file 1. Table S1: Positions on PAS and Euthanasia of all Identified US Medical and Surgical Societies.

\begin{abstract}
Abbreviations
AAHPM: American Academy of Hospice and Palliative Medicine; AAN: American Academy of Neurology; ACP: American College of Physicians; AMA: American Medical Association; AMDA: Society for Post-Acute and Long-term Care Medicine; APA: American Psychological Association; ASA: American Society of Anesthesiologists; NHPCO: National Hospice and Palliative Care Organization; PAD: Physician-assisted death; PAS: Physician-assisted suicide.
\end{abstract}

\section{Acknowledgements}

Not applicable.

\section{Authors' contributions}

JB contributed to study design, the collection and analysis of position statement data, and the writing and editing of the manuscript. CR contributed to position statement data collection and made major contributions to data organization. $\mathrm{CH}$ made contributions to data collection and organization as well as manuscript editing. PM contributed to and oversaw study design, data collection, position statement analysis, and the writing and editing of the manuscript. All authors have read, approved, and are accountable for the final manuscript.

\section{Funding}

This study had no funding source.

\section{Availability of data and materials}

All data generated or analyzed during this study are included in this published article and its supplementary information files.

Ethics approval and consent to participate

Not applicable.

Consent for publication

Not applicable (see cover letter).

\section{Competing interests}

The authors declare that they have no competing interests.

\section{Author details}

${ }^{1}$ Division of Hematology, Mayo Clinic, Rochester, MN, USA. ${ }^{2}$ Department of Internal Medicine, Mayo Clinic Health System-Franciscan Healthcare in La Crosse, 800 West Ave S, La Crosse, WI 54601, USA. ${ }^{3}$ Hamline University, St. Paul, MN, USA. ${ }^{4}$ Augsburg University, Minneapolis, MN, USA.

Received: 21 August 2019 Accepted: 28 October 2020

Published online: 03 November 2020

\section{References}

1. End of Life Option Act, ABX2-15 (2016).

2. Proposition 106, End of Life Options Act (2016).

3. Our Care, Our Choice Act (2019).

4. Maine Death With Dignity Act. In: 2019.

5. Oregon Death With Dignity Act (1994).

6. Act 39, Vermont Patient Choice and Control at the End of Life Act (2013).

7. Washington Assisted Death Initiative, Initiative 1000 (2008),

8. Death With Dignity Act of 2015.

9. Baxterv Montana, 27 Jan 2009 (2009).

10. Assisted Suicide Laws in the United States. Patients Rights Council. https ://www.patientsrightscouncil.org/site/assisted-suicide-state-laws/. Updated 6 Jan 2017. Accessed 16 Apr. 2019.

11. Euthanasia, assisted suicide and non-resuscitation on request. https:// www.government.nl/topics/euthanasia/euthanasia-assisted-suicide-andnon-resuscitation-on-request. Accessed 16 Apr. 2019.

12. Member Organizations of the AMA House of Delegates. American Medical Association. https://www.ama-assn.org/house-delegates/hod-organ ization/member-organizations-ama-house-delegates. Accessed 16 Apr. 2019.

13. Statement on Physician-Assisted Dying. American Academy of Hospice and Palliative Medicine. https://aahpm.org/positions/pad. Published 2016. Accessed 16 Apr. 2019.

14. Verma T, Renu, Gaur D. Tokenization and filtering process in RapidMiner. Int J Appl Inform Syst. 2014;7(2):16-8.

15. Medhat W, Hassan A, Korashy H. Sentiment analysis algorithms and applications: a survey. Ain Shams Eng J. 2014;5(4):1093-113.

16. Russell JA, Epstein LG, Bonnie RJ, et al. Lawful physician-hastened death: AAN position statement. Neurology. 2018;90(9):420-2.

17. Committee on Ethics. Committee opinion no. 617: end-of-life decision making. Obstet Gynecol. 2015;125(1):261-7.

18. Vizcarrondo FE. Neonatal euthanasia: the Groningen Protocol. Linacre Q. 2014;81(4):388-92.

19. Snyder Sulmasy L, Mueller PS, Ethics, Professionalism and Human Rights Committee of the American College of Physicians. Ethics and the Legalization of Physician-Assisted Suicide: An American College of Physicians Position Paper. Ann Intern Med. 2017;167(8):576-78. 
20. Physician-Assisted Suicide. American Medical Association. Code of Medical Ethics Opinion 5.7 Web site. https://www.ama-assn.org/delivering -care/ethics/physician-assisted-suicide. Accessed 16 Apr. 2019.

21. Euthanasia. American Medical Association. Code of Medical Ethics Opinion 5.8 Web site. https://www.ama-assn.org/delivering-care/ethics/eutha nasia. Accessed 16 Apr. 2019.

22. Physician Assisted Suicide. American Pharmacists Association. APhA Policy Manual Web site. https://www.pharmacist.com/policy-manua I?key=suicide\&op=search. Accessed 16 Apr. 2019

23. Position Statement on Medical Euthanasia. American Psychiatric Association. APA Official Actions Web site. https://www.psychiatry.org/home/ search-results?k=euthanasia. Published 2016. Accessed 16 Apr. 2019.

24. Resolution on Assisted Dying. American Psychological Association. https ://www.apa.org/about/policy/assisted-dying-resolution. Published 2017. Accessed 16 Apr. 2019.

25. Statement on Physician Nonparticipation in Legally Authorized Executions. American Society of Anesthesiologists. Standards and Guidelines Web site. https://www.asahq.org/standards-and-guidelines/state ment-on-physician-nonparticipation-in-legally-authorized-executions. Published 2006. Updated 26 Oct. 2016. Accessed 16 Apr. 2019.

26. Commentary and Resolution on Physician Assisted Suicide. National Hospice \& Palliative Care Organization. https://www.nhpco.org/sites/default/ files/public/PAS_Resolution_Commentary.pdf. Published 2005. Accessed 16 Apr. 2019
27. Position Statement on Care at the End of Life. American Medical Directors Association The Society for Post-Acute and Long-Term Care Medicine. https://paltc.org/amda-white-papers-and-resolution-position-statements /position-statement-care-end-life. Published 1997. Accessed 16 Apr. 2019.

28. Shih J. Interpreting the Score and Ratio of Sentiment Analysis. Twinword. https://www.twinword.com/blog/interpreting-the-score-and-ratio-ofsentiment/. Accessed 16 Apr. 2019.

29. KirkTW, Mahon MM, Palliative Sedation Task Force of the National H, Palliative Care Organization Ethics C. National Hospice and Palliative Care Organization (NHPCO) position statement and commentary on the use of palliative sedation in imminently dying terminally ill patients. J Pain Symptom Manag. 2010;39(5):914-23.

30. Quill TE, Back AL, Block SD. Responding to patients requesting physicianassisted death: physician involvement at the very end of life. JAMA. 2016;315(3):245-6.

31. Physician Assisted Suicide and Euthanasia. Christian Medical \& Dental Associations. https://cmda.org/physician-assisted-suicide/. Accessed 17 Apr. 2019.

\section{Publisher's Note}

Springer Nature remains neutral with regard to jurisdictional claims in published maps and institutional affiliations.
Ready to submit your research? Choose BMC and benefit from:

- fast, convenient online submission

- thorough peer review by experienced researchers in your field

- rapid publication on acceptance

- support for research data, including large and complex data types

- gold Open Access which fosters wider collaboration and increased citations

- maximum visibility for your research: over $100 \mathrm{M}$ website views per year

At BMC, research is always in progress.

Learn more biomedcentral.com/submissions 